\title{
Electrodeposition of Composite Coatings of $\mathrm{Cu} / \mathrm{AlO}(\mathrm{OH})$ Using Allyl Alcohol as an Additive
}

\author{
Thaís Guimarães de Lima Rezende ${ }^{a}$, Dalva Cristina Baptista do Lago ${ }^{a}$, Deborah Vargas Cesar ${ }^{b}$,
}

\author{
Lilian Ferreira de Senna ${ }^{a}$
}

\author{
${ }^{a}$ Corrosion and Electrochemistry Laboratory - LEC, Chemistry Institute, Universidade do Estado do \\ Rio de Janeiro - UERJ, Rua São Francisco Xavier, 524, Sala 427, Pavilhão Haroldo Lisboa da Cunha, \\ Maracanã, CEP 20559-013, Rio de Janeiro, RJ, Brazil \\ ${ }^{b}$ Chemical Engineering Materials Laboratory - LabMEQ, Universidade do Estado do Rio de Janeiro - \\ UERJ, Rua São Francisco Xavier, 524, Sala 427, Pavilhão Haroldo Lisboa da Cunha, Maracanã, CEP \\ 20559-013, Rio de Janeiro, RJ, Brazil
}

Received: December 11, 2016; Revised: August 03, 2017; Accepted: August 08, 2017

\begin{abstract}
In this work, composite coatings of $\mathrm{Cu} / \mathrm{AlO}(\mathrm{OH})$ were produced by electrodeposition on steel substrates using a pyrophosphate-based bath containing allyl alcohol as an additive. The electrodeposition of the composite coatings was carried out using a $2^{3}$ central composite design (CCD), aiming to verify the effects of the deposition parameters (previous stirring time $(\boldsymbol{t})$, the stirring speed $(\boldsymbol{S})$ and the current density $(j))$, considered the entry variables, on the electrochemical behavior of $\mathrm{Cu} / \mathrm{AlO}(\mathrm{OH})$ coating, the response variables of the CCD. The results indicated that a decrease of the parameters $\boldsymbol{j}$ and $\boldsymbol{S}$ directly influenced the values of $\boldsymbol{R}_{p}$ and $\boldsymbol{R}_{c t}$, leading to the production of protective coatings. The best result $\left(\boldsymbol{R}_{p}=211 \Omega\right.$ and $\left.\boldsymbol{R}_{c t}=221 \Omega\right)$ was obtained under conditions where $\boldsymbol{t}=120 \mathrm{~min}, \boldsymbol{S}=1300 \mathrm{rpm}$ and $\boldsymbol{j}=7 \mathrm{~A} \mathrm{~m}^{-2}$. Dispersed bohemite particles could be noted on the surface of the composite coating.
\end{abstract}

Keywords: Electrochemical co-deposition process, $\mathrm{Cu} / \mathrm{AlO}(\mathrm{OH})$, Composite coatings, Boehmite, Additive, Allyl alcohol

\section{Introduction}

Composite coatings are produced to achieve improved surface toughness, hardness, mechanical and electrochemical resistances, and several other properties. Many techniques ${ }^{1-5}$ can be used to produce highly uniform composite films, with good reproducibility, high adhesion, high deposition rate, low roughness and low cost $\mathrm{t}^{1,6-8}$.

Electrochemical co-deposition, also known as electro co-deposition, the most used technique to produce these coatings. It consists of incorporating nanoparticles or nanowires (generally, nonmetallic ones), intentionally added to the electrolyte, to the metallic matrix during the electrodeposition process. The main advantage of this technique is the possibility of producing thin coatings relatively free of pores ${ }^{9,10}$. Besides, the technique is inexpensive and can be conducted at room temperature and normal pressure with high deposition rate ${ }^{9-11}$. Although several models were proposed to explain the co-deposition phenomenon of inert particles added to an electrolyte to produce a composite coating during the electrodeposition, only two of them are well accepted in literature ${ }^{12-18}$. As a whole, these models deal with the mechanisms to stabilize the suspensions and the fact that the particles must stay suspended during all the electrodeposition process.
The "two-step adsorption model"13 consider that two different phenomena must be taken into account to explain the deposition of particles: electrophoresis and adsorption. In this model, the deposition of particles depends on both the current density and the concentration of particles in the bath. However, this model alone is not able to evaluate the effects of other parameters, such as the solution stirring or the bath temperature, for example, on the electrolytic co-deposition of these particles. The "five-step model" ${ }^{12}$ in turn, comprises the previously mentioned adsorption model and considers the mass transfer processes of the particles and the ionic species to the cathode surface. This last model showed that the co-deposition process depends on numerous variables, including the hydrodynamic conditions of the electrodeposition.

The influence of the deposition parameters, such as current density, the concentration of particles in the bath, the stirring of the suspension, the solution $\mathrm{pH}$ and temperature and the bath composition, on the electro co-deposition process and on the properties of the coating has been investigated by several works $s^{6-8,19,20}$. The influence of the applied current density values on the particle content in the coating and, consequently, on the coating properties, is the most reported parameter in the literature $5,7,9-11,19,21$. Additionally, it was verified that the use of continuous (DC) or pulsed ${ }^{16}$ current influenced on the anticorrosive performance of composite coatings ${ }^{22}$. 
Another usually studied parameter concerning the co-deposition of composite coatings is the stirring speed of the electrolytic bath b $^{3,9,23,24}$. For example, this parameter affected the amount of $\mathrm{CeO}_{2}$ particles (size between 15 and $20 \mathrm{~nm}$ ) in a nickel matrix composite coatings, which increased the hardness of the produced coatings ${ }^{3}$. The process of producing composite films is more complex than that used in the electrodeposition of alloys, since the particles of ceramic material to be embedded in the metallic matrix should be kept in suspension during the deposition process ${ }^{7,20,24}$. This feature requires that the electro co-deposition process should always occur under stirred conditions to prevent the precipitation of the particles ${ }^{1,3,7,23}$.

In general, if the stirring speed is slow, it prevents the dispersion of the particles, allowing their aggregation and precipitation. Additionally, slow stirring speed values are not able to carry all of the particles to the cathode ${ }^{7,19}$. On the other hand, if the stirring speed is quite fast, the particles do not have enough time to be trapped into the coating, resulting in a lower incorporation of particles ${ }^{19}$ and in the removal of those that are not completely adsorbed on the cathode $^{19,26,27}$. The speed values (low or fast) depend of the ceramic material used in each case.

As the electrolytic suspension used to co-deposit the composite coatings must be stable, the presence of a surfactant in the bath is another topic frequently studied to enhance the performance of the co-deposition process and to produce composite coatings presenting the desired properties ${ }^{6,22,25-28}$. For example, the increase of cetyltrimethyl ammonium bromide (CTAB) concentration enhanced the incorporation of $\mathrm{SiO}_{2}$ in the copper metallic matrix by modifying the surface charge of the nanoparticles (the negative initial charge turns into a positive one) and their hydrophilicity ${ }^{28}$. This effect leaded to an increase in the anticorrosive performance of the coating.

The co-deposition process is also influenced by the period of time that the particles are previously stirred in the electrodeposition solution, containing or not surfactants, before the electrodeposition starts. Although it is not usually investigated in the literature as a deposition parameter, it is possible to verify that composite coatings were produced after being previously stirred by periods ranging from 30 minutes to 24 hours ${ }^{2,21,22,29}$. Unfortunately, no explanation about this choice is mentioned in the literature.

The works presented in the literature always use univariate methods to accomplish their studies, where only one of the evaluated parameters is varied, while the others are kept constant. In practice, it means that the optimum conditions found in these experiments are empirical and can doubtfully represent the best conditions to obtain the desired properties ${ }^{30,31}$. Moreover, this procedure is always time- consuming, requiring a significant number of experiments and, most of the time, producing substantial amounts of wastewater. Additionally, the combined influence of the several parameters on the studied variables is not evaluated by these methodologies, indicating that the observed optimum levels should be considered carefulness ${ }^{30,32,33}$. Therefore, to ensure a greater reproducibility and quality of the composite coatings produced by electrodeposition, it is important the development of a scientific approach that leads to a better understanding of the deposition phenomena.

One way to obtain a better approximation of the optimized conditions is the use of experimental design tools, such as the response surface methodology, where all parameters are varied simultaneously, showing the responses of their synergistic and or antagonistic interactions ${ }^{31,34}$. These methodologies sharply reduce the number of experiments required for optimization of the process, as well as decrease the cost and volume of effluent generated. They also provide the necessary statistical inference for a better process efficiency ${ }^{34,35}$. In addition, it is possible to create new coating systems that can fulfill different industrial needs ${ }^{31,36,37}$. Nowadays, several reports can be found in the literature concerning the use of these methodologies to enhance the quality of electrodeposition baths or to achieve realistic optimized conditions ${ }^{30,32-34,36-41}$.

The microstructure of the composite coatings depends on both the metallic matrix and the second phase material. However, these coatings often present rough surfaces and defects, and additives can be added to the electrodeposition bath to improve morphological and anticorrosive properties, as it is usually used for metallic coatings ${ }^{41-43}$. These additives are organic compounds, whose functions are to refine the grains obtained in the electrodeposition process, reproduce the brightness of the original metal and promote the formation of layers without defects or cracks ${ }^{42,43}$. Although the use of these leveling agents could enhance the properties of composite coatings produced by electrodeposition, there are relatively few data in the literature concerning this topic ${ }^{18,28}$.

In the present work, composite $\mathrm{Cu} / \mathrm{AlO}(\mathrm{OH})$ coatings were produced on carbon steel substrates by electrochemical co-deposition using a pyrophosphate-based bath containing allyl alcohol as an additive. Allyl alcohol is a low molecular weight alcohol, reported as a brightening agent and tension reliever. This compound is commonly used as additive in the production of $\mathrm{Cu}$ coatings and $\mathrm{Cu}-\mathrm{Zn}$ alloy ${ }^{41,42}$ and has never been used as a levelling agent in electrodeposition of composite coatings. A $2^{3}$ central composite design was used to verify the effects of three deposition parameters (current density, $\boldsymbol{j}$, stirring speed of the rotating disc electrode during the co-deposition process, $S$, and the stirring time before the co-deposition process starts, $\boldsymbol{t}$ ) on the studied deposition variables (polarization resistance, $\boldsymbol{R}_{p}$ and the charge transfer resistance, $\boldsymbol{R}_{c t}$ ). Our aim was to find the best conditions, using the studied electrodeposition bath, to produce anticorrosive composite coatings in $\mathrm{Na}_{2} \mathrm{SO}_{4} 0.10 \mathrm{~mol} \mathrm{~L}^{-1}$ medium, and to verify the effects of the different parameters on the deposition processes of metal/ceramic particle coatings. 


\section{Experimental Procedures}

\subsection{Preparation of the electrolytic cell: electrodes and deposition electrolyte}

A three-electrode cell was used to study the electrodeposition of the composite coating, in which the AISI 1020 carbon steel disks were the working electrodes, mounted in a rotating disk electrode (RDE) apparatus (AUTOLAB RDE-2). A $3.21 \mathrm{x}$ $10^{-4} \mathrm{~m}^{2}$ copper plate was used as the counter electrode, while the reference electrode was a saturated sulfate mercurous electrode $\left(\mathrm{Hg} / \mathrm{Hg}_{2} \mathrm{SO}_{4}, \mathrm{SSE}\right)$.

The steel electrodes were first polished with emery paper (100 to $600 \mathrm{mesh}$ ), washed with deionized water and alcohol, and finally dried, before immersion in the electrolytic solution. The counter electrode was etched in a solution of $\mathrm{HNO}_{3} 10 \% \mathrm{v} / \mathrm{v}+\mathrm{H}_{2} \mathrm{SO}_{4} 20 \% \mathrm{v} / \mathrm{v}$ for 2 minutes, washed with distilled water and alcohol and dried, before immersion in the electrolyte. Finally, the reference electrode was washed with water and dried with a tissue before immersion in the deposition bath.

The electrolytic solution used to produce the composite coatings was composed by $0.02 \mathrm{~mol} \mathrm{~L}^{-1}$ of copper sulfate $\left(\mathrm{CuSO}_{4}\right), 0.90 \mathrm{~mol} \mathrm{~L}^{-1}$ of potassium pyrophosphate $\left(\mathrm{K}_{4} \mathrm{P}_{2} \mathrm{O}_{7}\right)$ and $0.01 \mathrm{~mol} \mathrm{~L}^{-1}$ of allyl alcohol (AA), in which $20.00 \mathrm{~g} \mathrm{~L}^{-1}$ of bohemite particles $(\mathrm{AlO}(\mathrm{OH}), 25 \mathrm{~nm})$ were added. The bath composition was based on previous studies to produce copper and copper alloys coatings ${ }^{44,45}$, as well as on our first results used to produce composite coatings ${ }^{46}$. In order to guarantee that the particles would be suspended during the electrochemical experiments, the suspension was stirred ( $\sim 1000 \mathrm{rpm})$, before each experiment, for different stirring time (ranging from 1 to 6 hours), using a magnetic stirrer.

\subsection{Electrochemical co-deposition and characterization of the $\mathrm{Cu} / \mathrm{AlO}(\mathrm{OH})$ composite coatings}

\subsubsection{Cathodic polarization curves}

Cathodic polarization curves of carbon steel disks (exposed area $=7.85 \times 10^{-5} \mathrm{~m}^{2}$ ) were obtained in the co-deposition bath, previously stirred from 1 to 6 hours, as described in Section 3.1, using the three-electrode cell, also mentioned in the same section. The potential was ranged from the open circuit potential $\left(E_{\text {ocp }}\right)$ to $-2.0 \mathrm{~V}_{\mathrm{SSE}}$, with a potentiostat/galvanostat AUTOLAB PGSTAT 302N, at 25 ${ }^{\circ} \mathrm{C}$, using a scan rate of $1.00 \mathrm{mV} \mathrm{s}^{-1}$, under different stirring speeds (1000 and $1200 \mathrm{rpm})$. The aim of this experiment was to verify which conditions, in terms of current density $(\boldsymbol{j})$, RDE stirring speed $(\boldsymbol{S})$ and the stirring time before the co-deposition process starts $(\boldsymbol{t})$, would be used to produce the composite coatings by using the experimental design.

\subsubsection{Electrochemical co-deposition}

The electrodeposition experiments were performed galvanostaticaly using the same solution, electrolytic cell, and equipments mentioned in Section 2.1 and sub-section 2.2.1. However, the exposed area of the steel working electrode used in the present experiments was changed to $2.54 \times 10^{-4} \mathrm{~m}^{2}$. Using the current densities selected form the polarization curves (sub-section 2.2.1), the electrodeposition time for each experiment was calculated based on the Faraday's Law, to produce a coating with a theoretical mass $=5 \mathrm{mg}$. It is important to mention that this law is related to the deposited mass of species reduced by electrolysis, only. Therefore, the copper reduction process was the unique reaction considered for this theoretical calculation, since the other possible electrolytic process, the hydrogen evolution reaction (HER) from water, would not contribute to a mass deposited on the substrate. Additionally, considering the most accepted models ${ }^{12,13}$, there is no electrolysis involved in the deposition of the particles.

In order to optimize the production of composite coatings, a $2^{3}$ experimental central composite design (CCD), with central axial points, was employed ${ }^{31}$. It means that the three evaluated parameters (the current density, $\boldsymbol{j}$, the stirring speed of the RDE during the co-deposition process, $\boldsymbol{S}$, and the stirring time before the co-deposition process starts, $\boldsymbol{t}$ ) were simultaneously varied between the two levels, -1 and +1 . The -1 level represents the lowest value of the studied parameter, while the +1 level corresponds to its highest value $^{47}$. The experimental design matrix, as well as the codified and the real values of the studied parameters, are shown in Table 1. Besides the two-level full factorial design, a CCD also presents a star design $(\alpha)$ and a central point to investigate the factors ${ }^{48,49}$. The star design at the factor levels $0,-\alpha(-1.682)$ and $+\alpha(+1.682)$, and the central point at the factor levels 0 , are also present in Table 1 .

A quadratic model was applied in order to evaluate quantitatively the effects of $\boldsymbol{j}, \boldsymbol{t}$ and $\boldsymbol{S}$, on the polarization resistance $\left(\boldsymbol{R}_{p}\right)$ and the charge transfer resistance $\left(\boldsymbol{R}_{c t}\right)$ of the composite coating/steel substrate system. A commercial software package (STATISTICA for Windows, release 7.0, Statsoft) was used for the experimental data regression analysis. Equation (1) represents the corresponding complete quadratic surface model between the system responses and the studied factors.

$$
\begin{aligned}
\hat{y}= & b_{0}+b_{1} x_{1}+b_{2} x_{2}+b_{3} x_{3}+b_{11} x_{1}^{2}+b_{22} x_{2}^{2}+ \\
& +b_{33} x_{3}^{2}+b_{12} x_{1} x_{2}+b_{13} x_{1} x_{3}+b_{23} x_{2} x_{3}
\end{aligned}
$$

where $\hat{y}$ is the predicted variable $\left(\boldsymbol{R}_{p}\right.$ and $\left.\boldsymbol{R}_{c t}\right)$, while $x_{1}$, $x_{2}$ and $x_{3}$ correspond to the deposition parameters $\boldsymbol{S}, \boldsymbol{t}$ and $\boldsymbol{j}$, respectively. The term $x_{i} x_{j}$ represents the interaction between two of the studied parameters and the $b_{i s}$ are the coefficients 
Table 1. Composite design $2^{3}$ experimental matrix, showing codified and normal values of the variables studied.

\begin{tabular}{|c|c|c|c|c|c|c|}
\hline Run $\mathrm{N}^{\circ}$ & $\begin{array}{c}S \text { (codified } \\
\text { values) }\end{array}$ & $\begin{array}{c}t \text { (codified } \\
\text { values) }\end{array}$ & $\begin{array}{c}j \text { (codified } \\
\text { values) }\end{array}$ & $S(\mathrm{rpm})$ & $t(\min )$ & $j\left(\mathrm{~A} \mathrm{~m}^{-2}\right)$ \\
\hline 1 & -1 & -1 & -1 & 1000 & 120 & 7.0 \\
\hline 2 & -1 & -1 & +1 & 1000 & 120 & 21.0 \\
\hline 3 & -1 & +1 & -1 & 1000 & 360 & 7.0 \\
\hline 4 & -1 & +1 & +1 & 1000 & 360 & 21.0 \\
\hline 5 & +1 & -1 & -1 & 1300 & 120 & 7.0 \\
\hline 6 & +1 & -1 & +1 & 1300 & 120 & 21.0 \\
\hline 7 & +1 & +1 & -1 & 1300 & 360 & 7.0 \\
\hline 8 & +1 & +1 & +1 & 1300 & 360 & 21.0 \\
\hline 9 & 0 & 0 & 0 & 1150 & 240 & 14.0 \\
\hline 10 & 0 & 0 & 0 & 1150 & 240 & 14.0 \\
\hline 11 & 0 & 0 & 0 & 1150 & 240 & 14.0 \\
\hline 12 & -1.682 & 0 & 0 & 898 & 240 & 14.0 \\
\hline 13 & +1.682 & 0 & 0 & 1402 & 240 & 14.0 \\
\hline 14 & 0 & -1.682 & 0 & 1150 & 38 & 14.0 \\
\hline 15 & 0 & +1.682 & 0 & 1150 & 441 & 14.0 \\
\hline 16 & 0 & 0 & -1.682 & 1150 & 240 & 2.2 \\
\hline 17 & 0 & 0 & +1.682 & 1150 & 240 & 25.8 \\
\hline
\end{tabular}

of the equation. Statistical tests $(p=0.05)$ were then used to verify whether the analyzed effects were statistically significant. In the equations presented in this work, only the parameters that affected this system at a level of statistical significance $(p<0.05)$ will be shown. It is important to point out that even though some individuals trends could be observed in how the studied parameters $(\boldsymbol{S}, \boldsymbol{t}$, and $\boldsymbol{j})$ influenced the response variables $\left(\boldsymbol{R}_{p}\right.$ and $\left.\boldsymbol{R}_{c t}\right)$, the final results concerning the influence of the studied parameters were obtained using the response surface methodology, which takes into account all the responses observed for each effect. These response surfaces are represented as three-dimensional diagrams, in which the studied electrodeposition parameters (the entry variables) are presented in their codified values (Table 1) in the $\mathrm{x}$ and $\mathrm{y}$ axes, while the response variables are presented in the $\mathrm{z}$-axis, with their real values.

\subsubsection{Electrochemical evaluation}

The $\mathrm{Cu} / \mathrm{AlO}(\mathrm{OH})$ composite coatings produced under the conditions described in Table 1 were electrochemically analyzed using a potentiostat/galvanostat AUTOLAB PGSTAT 302N and the rotating electrode AUTOLAB RDE-2, under controlled stirring (100 rpm). The cell was composed by the working electrode (i.e., each coating/ substrate system), a platinum spiral as the counter electrode and the saturated mercurous sulfate electrode (SSE) as the reference electrode. All the experiments were performed at $25^{\circ} \mathrm{C}$, in a $0.10 \mathrm{~mol} \mathrm{~L}^{-1} \mathrm{Na}_{2} \mathrm{SO}_{4}$ solution. This medium was chosen to simulate an industrial environment, in which these coatings can be used.
The open circuit potential $\left(\boldsymbol{E}_{\text {ocp }}\right)$ of each coating/substrate system was determined after 1 hour of stabilization in the electrolyte before the experiments being performed. Initially, the $\mathrm{Cu} / \mathrm{AlO}(\mathrm{OH})$ composite coatings/steel substrate systems were evaluated using electrochemical impedance spectroscopy (EIS) at the $\boldsymbol{E}_{\text {ocp }}$, with $10 \mathrm{mV}$ of amplitude and a frequency range from $100 \mathrm{kHz}$ to $1 \mathrm{mHz}$. The EIS analysis was also performed for the bare steel substrate and copper coating, as comparison. The charge transfer resistance $\left(\boldsymbol{R}_{c t}\right)$ and the constant phase element (CPE), used to calculate the double layer capacitance $\left(\boldsymbol{C}_{d l}\right)$, were obtained by simulating the EIS data using the equivalent circuit presented in Figure 1.

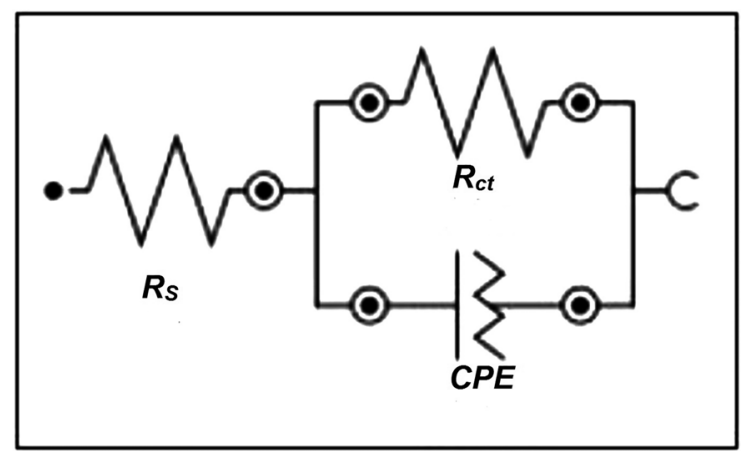

Figure 1. Equivalent circuits used to simulate the experimental EIS data.

Then, the polarization resistances of the coating/substrate systems $\left(\boldsymbol{R}_{p C}\right)$ were obtained by varying linearly the potential around the $\boldsymbol{E}_{\text {ocp }}\left( \pm 10 \mathrm{mV}_{\mathrm{SSE}}\right)$, with a scan rate of $0.1 \mathrm{mV} \mathrm{s}^{-1}$. 
The slope of these curves were used to determinate the $\boldsymbol{R}_{p}$ values. The polarization resistance experiments were also performed for the bare steel and copper coating in the same electrolyte, for comparison.

The coatings presenting the best (highest values of $\boldsymbol{R}_{p}$ and $\boldsymbol{R}_{c t}$ ) and the worse (highest values of $\boldsymbol{R}_{p}$ and $\boldsymbol{R}_{c t}$ ) anticorrosive performances were selected to be morphologically, chemically, mechanically and microstructurally evaluated.

\subsubsection{Morphological analysis}

The surface morphologies of the selected coatings were evaluated using a scanning electron microscopy (SEM) JEOL JSM-6510LV. The samples were cleaned with alcohol, dried and then adapted to the stub with a conductive tape. The analysis was carried out in high vacuum, using secondary electron mode and voltages of $20 \mathrm{kV}$.

\subsubsection{Chemical composition of the coatings}

The selected composite coatings were also evaluated quantitatively by energy dispersive spectrometry of X-rays, EDS (EDS IFRX), coupled to the microscope TM 3000- Hitachi. The analysis of each selected coating/substrate system was carried out in three different regions of the coatings, with a magnification of $500 \mathrm{X}$.

\subsubsection{Microstructural analysis}

The structure of the selected composite coatings was analyzed in a BROOKER D8 X-ray diffractometer (XRD). The incidence angle was $2^{\circ}$, and the diffraction angle $(2 \theta)$ was varied between $20^{\circ}$ and $120^{\circ}$ with a step size of $0.02^{\circ}$ and counting time of 1 second.

\subsubsection{Hardness analysis}

A NANOVEA N3 LINE nanohardness equipment was used to evaluate the hardness of the selected composite coatings. The surfaces of all coatings were indented with a load of $10 \mathrm{mN}$ for 20 seconds. The thickness of indentation was always smaller than $10 \mathrm{~nm}$. The measurements were obtained in triplicate.

\section{Results and Discussion}

\subsection{Cathodic polarization curves}

Figure 2 shows the cathodic polarization curves of the steel substrate in the electrolytic solution describe in section 3.1 using different $\boldsymbol{S}$ and $\boldsymbol{t}$ values. These polarization curves were also used to select the parameter used for the electrodeposition experiments, shown in Table 1.

There are few differences in the curves profiles, independent of the $\boldsymbol{S}$ or $\boldsymbol{t}$ values used. Even though, it is possible to verify that the curves obtained at the stirring speeds of 1000 and $1200 \mathrm{rpm}$ showed variations with the previous stirring time in the region between $-1.10 \mathrm{~V}_{\mathrm{SSE}}$ and $-1.40 \mathrm{~V}_{\mathrm{SSE}}$, where the
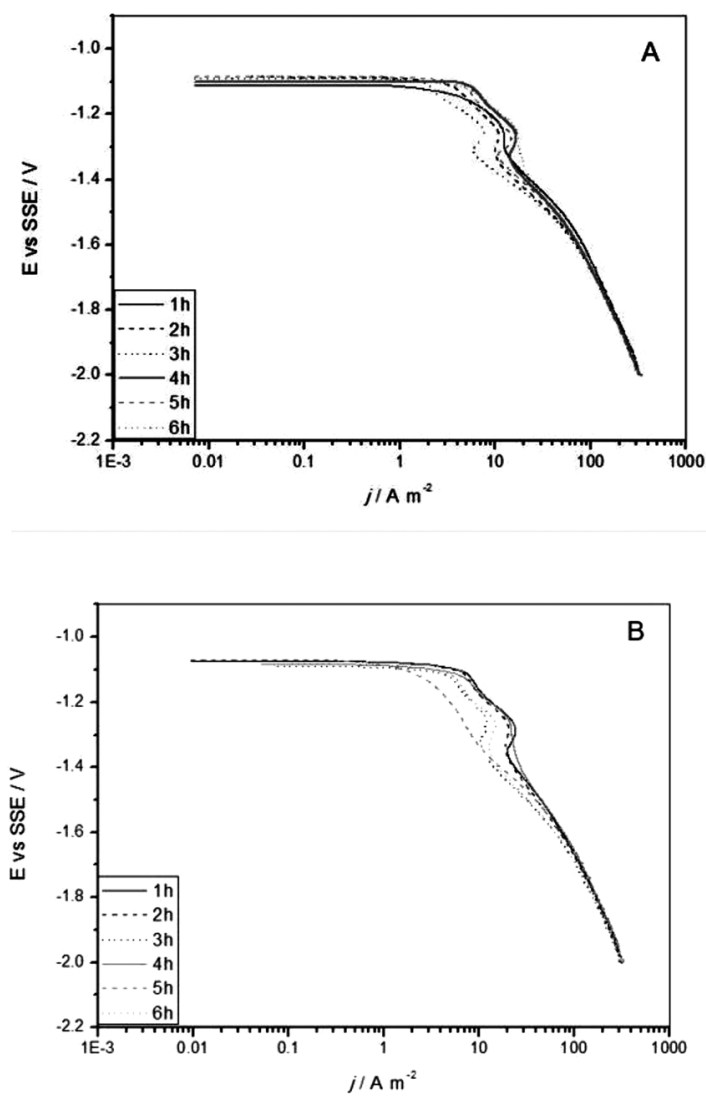

Figure 2. Effect of the preparation time in the polarization curves of the steel substrate in solution 4 of Table 1, containing $20 \mathrm{~g} \mathrm{~L}^{-1}$ of boehmite. (A) Stirring speed $=1000 \mathrm{rpm}$; (B) Stirring speed $=$ $1200 \mathrm{rpm}$.

copper deposition is considered controlled by mass transfer ${ }^{44,46}$. These results indicate that the previous stirring time may affect this step of copper deposition process. Moreover, the variations were not linear with the increasing in $t$ and differed for each $\boldsymbol{S}$ values studied, as well. As these two parameters are directly related to the stability of the particles in the suspension, these results may indicate that the presence of the particles in the bath is affecting the transport of $\mathrm{Cu}$ ions to the electrode surface. This effect was expected, as the incorporation of boehmite particles in the coatings is likely promoted because they are carried to the electrode surface by the metallic ion solvation spheres ${ }^{8}$.

\subsection{Electrochemical co-deposition and characterization of the $\mathrm{Cu} / \mathrm{AlO}(\mathrm{OH})$ composite coatings}

All composite coatings produced under the conditions shown in Table 1 were adherent and presented pink color. The anticorrosive performance of these layers was statistically evaluated considering the linear polarization resistance $\left(\boldsymbol{R}_{p}\right)$ and the charge transfer resistance $\left(\boldsymbol{R}_{c t}\right)$ of the coatings. 


\subsubsection{Linear polarization resistance $\left(\boldsymbol{R}_{p}\right)$}

The magnitude of each effect is shown in bars and the transverse line corresponding to the value of $p=0.05$ indicates how large the effect should be to have statistical significance. It was observed, with $95 \%$ of confidence, that some parameters, such as $\boldsymbol{S}$ and $\boldsymbol{j}$ (quadratic mode), $\boldsymbol{j}$ (linear mode), the $\boldsymbol{S} \times \boldsymbol{t}$, and the $\boldsymbol{t} \times \boldsymbol{j}$ interactions, statistically influenced this variable, as shown by the Pareto diagram (Figure 3A) and Equation (2).

$$
R_{p}=122.3+15.3 S^{2}-6.7 j+9.2 j^{2}-8.9 S t+7.2 t j
$$

It was verified that the quadratic effects of $S(p<0.007)$ and $\boldsymbol{j}(\mathrm{p}<0.02)$ on $\boldsymbol{R}_{p}$ are positive. It means that very high (positive or negative) values of $\boldsymbol{S}$ or $\boldsymbol{j}$ (out of the range of this work) can enhance the studied variable. An increase in $\boldsymbol{S}$ is related to the stability of the dispersion, while an increase in $\boldsymbol{j}$ is associated to the increase in the boehmite content in the coating ${ }^{19,46,50}$. Thus, a decrease of $\boldsymbol{S}$ or $\boldsymbol{j}$ may be related to a decrease in the boehmite in the coating. In addition, the linear effect of $\boldsymbol{j}(\mathrm{p}<0.03)$ is negative (Equation (2)) which means that an increase in $\boldsymbol{R}_{p}$ values can be obtained by decreasing this parameter. Considering these results, the response surface presented in Figure 3B indicates that coatings produced using high values of $\boldsymbol{S}$ and small values of $\boldsymbol{j}$ exhibit higher anticorrosive ability.

Both $\boldsymbol{S}$ and $\boldsymbol{t}$ parameters are related to the stability of bohemite particles in the suspension ${ }^{19,21,46}$ : high values of $\boldsymbol{S}$ and $\boldsymbol{t}$ would promote a stable dispersion and the particles could be carried to the cathode to be trapped on the metallic matrix during the reduction process. However, in the present study, the $\boldsymbol{S}$ and $\boldsymbol{t}$ interaction ( $\mathrm{p}<0.03$ ) is negative, indicating that anticorrosive coatings could be obtained by varying $S$ and $t$ in opposite directions (that is, increasing $\boldsymbol{S}$ and decreasing $\boldsymbol{t}$ or vice-versa). In fact, the response surface presented in Figure $3 \mathrm{C}$ shows that anticorrosive coatings could be produced using high values of $\boldsymbol{S}$ and low values of $\boldsymbol{t}$. On the other hand, the effect of the interaction between $\boldsymbol{t}$ and $\boldsymbol{j}(\mathrm{p}<0.04)$ on $\boldsymbol{R}_{p}$ is positive. This result suggests that a simultaneous variation of $\boldsymbol{t}$ and $\boldsymbol{j}$ in the same direction may promote the anticorrosive performance of the produced coatings. Therefore, it can be seen, in Figure 3D, that a simultaneous decrease in $\boldsymbol{t}$ and $\boldsymbol{j}$ produced the most resistant coatings.

Based on these results, a coating produced using high values of $\boldsymbol{S}$ and low values of $\boldsymbol{j}$ and $\boldsymbol{t}$ could act as a protective coating. The increase in the parameter $\boldsymbol{S}$ seems to favor the bohemite deposition in the coating, as well as the increase in the $\boldsymbol{R}_{p}$ value. In fact, this parameter presents the highest significant influence on the measured variable $(\mathrm{p}<0.007)$.
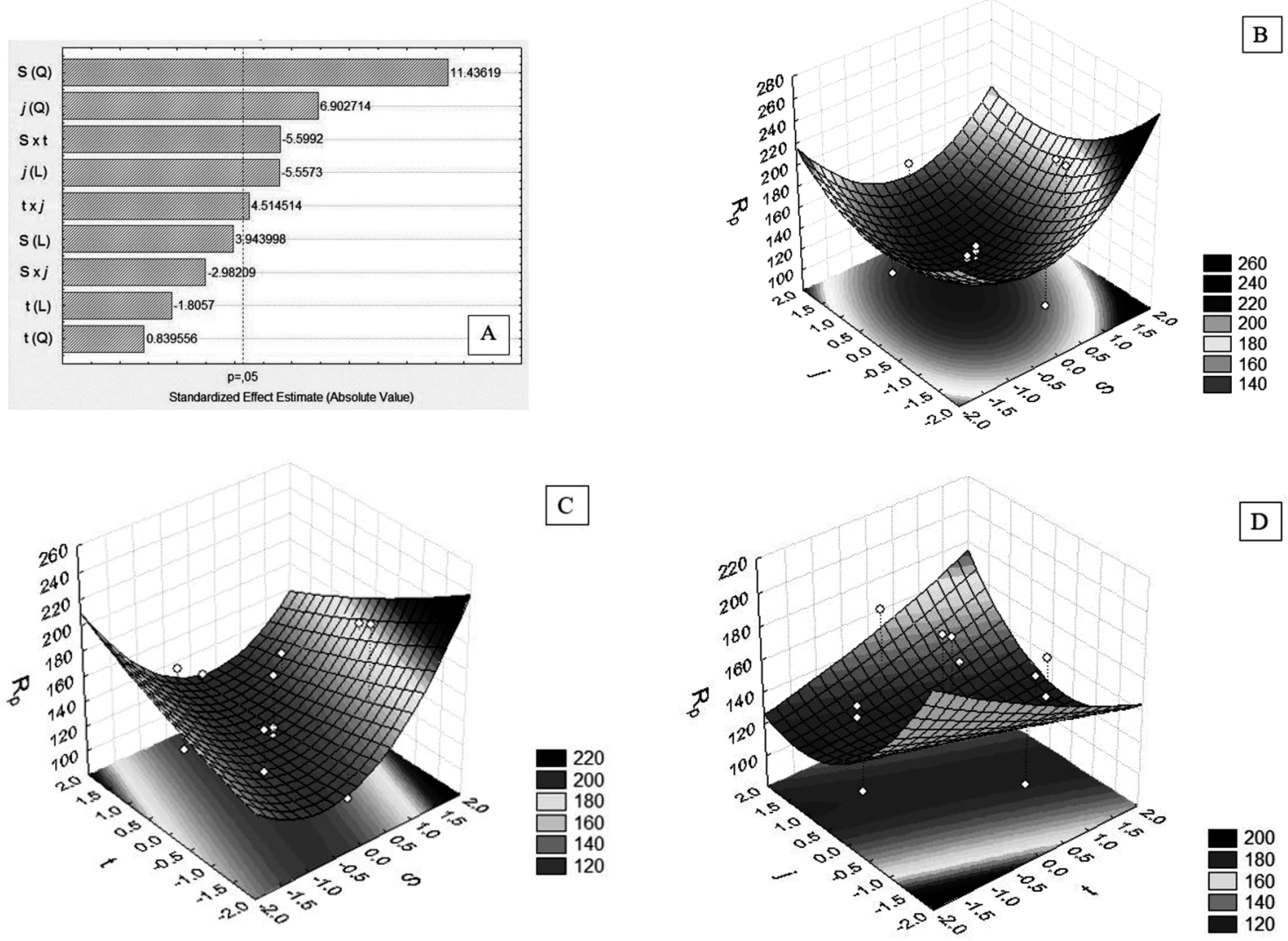

Figure 3. Fitted surfaces of standardized effects for $\boldsymbol{R}_{\boldsymbol{p}}$ : (A) Pareto diagram; (B) Effects of $\boldsymbol{j}$ and $\boldsymbol{S}$;(C) Effects of $\boldsymbol{t}$ and $\boldsymbol{S}$; (D) Effects of $\boldsymbol{j}$ and $\boldsymbol{t}$. 
A simultaneous increase of $\boldsymbol{t}$ and $\boldsymbol{j}$ could enhance the amount of bohemite in the coating ${ }^{19,21,46}$. However, when AA is present in the bath, the $\boldsymbol{j}$ and $\boldsymbol{t}$ parameters have decreased simultaneously in order to increase the $\boldsymbol{R}_{\boldsymbol{p}}$. Noteworthy, although high values of $\boldsymbol{S}$ can keep the particles suspended, low values of $\boldsymbol{t}$ may decrease the stabilization of the particles ${ }^{21}$, while low values of $\boldsymbol{j}$ favor copper deposition in a bath containing $\mathrm{AA}^{41}$.

As a leveling agent used for metallic coatings, AA decreases the internal stress of the coating/substrate system, which generally favors the production of coatings presenting small grain size, without defects, pores or cracks ${ }^{51,52}$. The presence of leveling additives in the co-deposition bath may interfere directly on the amount of the particles in the coating and on its morphology ${ }^{18,28}$. Therefore, it is possible that the presence of AA in the bath changed the deposition conditions to avoid the production of rough and porous coatings, which could decrease their $\boldsymbol{R}_{p}$ values.

Considering this, the coating presenting the best $\boldsymbol{R}_{p}$ value was that produced under the conditions of Experiment $5\left(\boldsymbol{j}=7.0 \mathrm{~A} \mathrm{~m}^{-2}, \boldsymbol{S}=1300 \mathrm{rpm}\right.$ and $\left.\boldsymbol{t}=120 \mathrm{~min}\right)$, as shown in Table 2.

\subsubsection{Charge Transfer Resistance $\left(\boldsymbol{R}_{c t}\right)$ of composite coatings}

The $\boldsymbol{R}_{c t}$ values for the coating/substrate system were obtained by simulating the EIS data using the equivalent circuit shown in Figure 1. This circuit consists of the solution resistance $\left(\mathrm{R}_{\mathrm{s}}\right)$ and a constant phase element (CPE) in parallel with the charge transfer resistance $\left(\boldsymbol{R}_{c t}\right)$. This procedure was also used to calculate the double layer capacitance $\left(\mathrm{C}_{\mathrm{dl}}\right)$ values (Equation 3). Only the $\boldsymbol{R}_{c t}$ values were used as response variable of the experimental design, once the $\mathrm{C}_{\mathrm{dl}}$ is obtained from the $\mathrm{R}_{\mathrm{ct}}$ values using Equation (3).

$$
C_{d l}=C P E^{1 / N} \cdot R_{c t}^{\left(\frac{1}{N}-1\right)}
$$

The results concerning the responses of $\boldsymbol{R}_{c t}$ (Figure 4) show, with $95 \%$ confidence, that the quadratic effect of $\boldsymbol{S}$ $(\mathrm{p}<0.02)$ and the interaction between $\boldsymbol{t}$ and $\boldsymbol{j}(\mathrm{p}<0.03)$ are positive, while the linear effect of $\boldsymbol{j}(\mathrm{p}<0.03)$ are negative. These effects are shown in Figure 4A and Equation (4).

$$
R_{c t}=124.8+12.5 S^{2}-10.2 j+13.1 t j
$$

As expected, these results present the same trends observed earlier for the $\boldsymbol{R}_{p}$ measurements. Therefore, the response surfaces concerning the interactions between $\boldsymbol{j}$ and $\boldsymbol{S}, \boldsymbol{t}$ and $\boldsymbol{S}$, and $\boldsymbol{j}$ and $\boldsymbol{t}$ (Figures 4B, 4C and 4D, respectively) show that high values of $\boldsymbol{R}_{c t}$ could be obtained by increasing $\boldsymbol{S}$ and decreasing $\boldsymbol{j}$ and $\boldsymbol{t}$.

Even though high values of $\boldsymbol{R}_{c t}$ may indicate that protective coatings were obtained, high values of $\mathrm{C}_{\mathrm{dl}}$ suggest that these coatings may be porous or conductive, permitting that the substrate be attacked by the electrolyte ${ }^{53}$. The $\mathrm{C}_{\mathrm{dl}}$ values calculated in the present experiments ranged from $1.6 \times 10^{-6}$ to $2.3 \times 10^{-2} \mathrm{~F} \mathrm{~cm}^{-2}$, depending on the experimental conditions. The lowest and highest $\mathrm{C}_{\mathrm{dl}}$ values were observed for the coatings produced under the conditions of Experiment $5(j=$ $7.0 \mathrm{~A} \mathrm{~m}^{-2}, \boldsymbol{S}=1300 \mathrm{rpm}$ and $\boldsymbol{t}=120 \mathrm{~min}$ ) and Experiment 14 $\left(\boldsymbol{j}=14.0 \mathrm{~A} \mathrm{~m}^{-2}, \boldsymbol{S}=1150 \mathrm{rpm}\right.$ and $\left.\boldsymbol{t}=38 \mathrm{~min}\right)$, respectively (Table 2). This result confirms that the best anticorrosive performance was verified for the coating produced under the conditions predicted by the model. Considering the conditions of Experiment 14, the increase in $\boldsymbol{j}$ and the decrease in $\boldsymbol{S}$, may explain the worse results verified for the coating produced using the conditions of this experiment, when compared to Experiment 5. Although a decrease in $\boldsymbol{t}$ value was also observed in Experiment 14 (codified $\boldsymbol{t}$ value $=-1,682$ ), it is possible that $\boldsymbol{t}=38 \mathrm{~min}$ was not enough to keep the particles suspended during all the electrodeposition process.

\subsection{Evaluation of selected coatings}

Considering the electrochemical results shown in Section $3.2\left(\boldsymbol{R}_{p}\right.$ and $\left.\boldsymbol{R}_{c t}\right)$, the composite coating/substrate systems produced under the conditions that resulted in the best (Experiment 5) and the worse (Experiment 14) anticorrosive performances were produced and evaluated, concerning their morphology, microstructure, chemical composition and hardness. These results are also presented in Table 2.

\subsubsection{Microstructure analysis}

The X-ray diffractograms for the selected composite coatings $\mathrm{Cu} / \mathrm{AlO}(\mathrm{OH})$ are presented in Figure 5.

In general, most of the coatings produced electrolytically from different solutions usually consist of fine crystals that are not uniform concerning the composition. Consequently, the crystal lattices exhibit a high degree of distortions caused by the formation of non-equilibrium phases on the substrate, which turns it difficult the evaluation of these deposits by X-ray. In some cases, the identification of the formed phases cannot be obtained completely ${ }^{45,51}$. All of the coatings analyzed in the present work were produced at room

Table 2. Anticorrosive performances chemical composition and hardness values of selected composite coatings.

\begin{tabular}{cccccccccc}
\hline Exp. & $A(\mathrm{rpm})$ & $t(\mathrm{~min})$ & $j\left(\mathrm{~A} \mathrm{~m}^{-2}\right)$ & $R_{p}(\Omega)$ & $R_{c t}(\Omega)$ & $C_{d l}\left(\mathrm{~F}_{\mathrm{cm}}\right)^{2}$ & $\%$ wt. Cu & $\%$ wt. AlO $(\mathrm{OH})$ & Hardness $(\mathrm{HV})$ \\
\hline 5 & 1300 & 120 & 7.0 & 211.05 & 221.00 & $1.6 \times 10^{-6}$ & 99.790 & 0.210 & $180.08 \pm 6.88$ \\
14 & 1150 & 38 & 14.0 & 109.54 & 121.00 & $2.3 \times 10^{-2}$ & 99.717 & 0.283 & $305.19 \pm 9.29$ \\
Steel & - & - & - & 107.30 & 96.30 & $7.9 \times 10^{-3}$ & - & - & $117.28 \pm 5.68$ \\
$\mathrm{Cu}$ & - & - & 7.0 & 184.02 & 201.00 & $2.7 \times 10^{-3}$ & - & - & $219.00 \pm 12.82$ \\
\hline
\end{tabular}




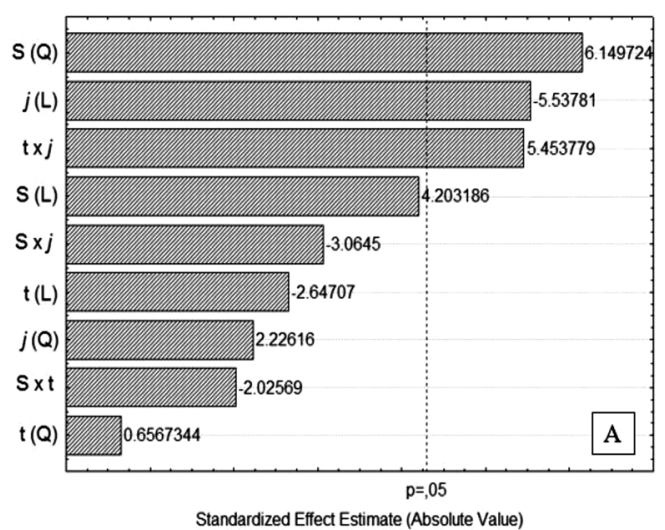

C

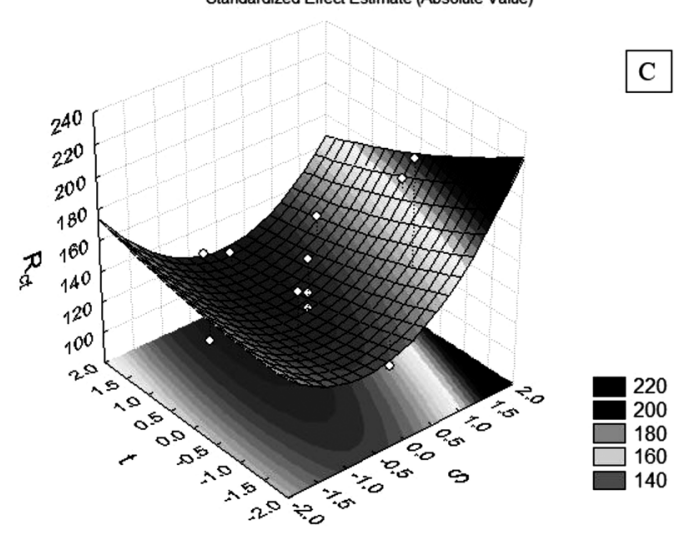

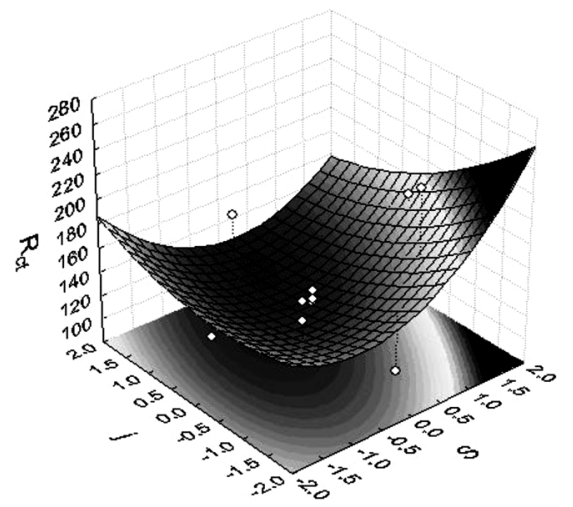

B

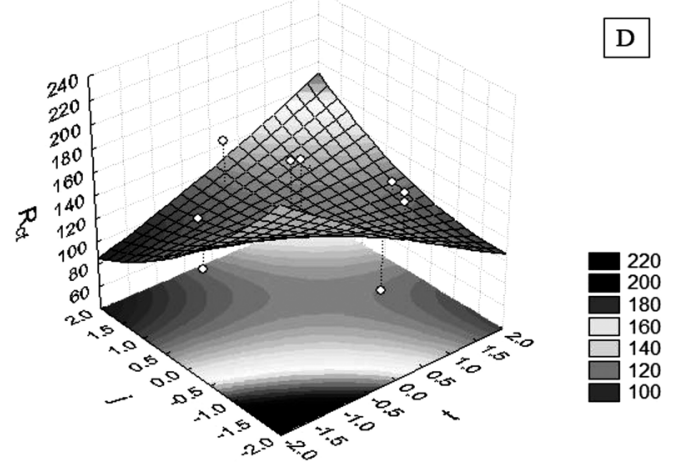

Figure 4. Fitted surfaces of standardized effects for $\boldsymbol{R}_{\boldsymbol{c}}$ : (A) Pareto diagram; (B) Effects of $\boldsymbol{j}$ and $\boldsymbol{S}$; (C) Effects of $\boldsymbol{t}$ and $\boldsymbol{S}$; (D) Effects of $\boldsymbol{j}$ and $\boldsymbol{t}$.

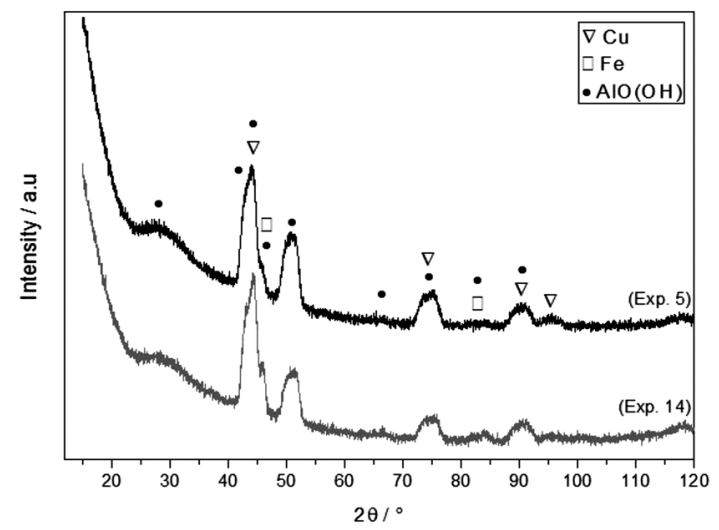

Figure 5. X-Ray diffractograms of the $\mathrm{Cu} / \mathrm{AlO}(\mathrm{OH})$ composite coatings produced from selected experiments.

temperature, and the thermal mismatch could contribute to macroscopic residual stress and to the microhardness of the electrodeposited layers ${ }^{51,54}$. Therefore, non-cataloged crystalline phases can be obtained.

Low intensity diffraction lines can be observed, likely because the coatings present small grain size due to the embedding of the boehmite nanoparticles in the copper crystals, which may disorder the crystalline growth of the metallic coating and facilitates a nanocrystalline structure ${ }^{10}$.
In addition, adsorbed nanoparticles may provide new nucleation sites for the copper ions ${ }^{9,10,28}$, further refining the microstructure $e^{9,10,21,28}$. The XRD pattern confirms that the electrodeposited composite coatings are composed by both copper and boehmite. However, it is necessary a detailed analysis of the XRD patterns to understand the effect of boehmite reinforcement on the development of the coating microstructure and microtexture.

It is possible to observe that the selected $\mathrm{Cu} / \mathrm{AlO}(\mathrm{OH})$ composite coatings present wide diffraction lines, corresponding to $\mathrm{Cu}$ (111) (JCPDS 04-0836) and to $\mathrm{AlO}(\mathrm{OH})(120)$ and (121) (JCPDS 05-0355). Moreover, the XRD diffractograms of the composite coatings suggest that the $\mathrm{AlO}(\mathrm{OH})$ are embedding in the copper metallic matrix, presenting diffraction lines at different $2 \theta$ values, as shown in Table 3 .

The XRD patterns revealed differences in the relative intensities of the $\mathrm{AlO}(\mathrm{OH})$ peaks. Concerning the results shown in Figure 5, the peak at $2 \theta \cong 46^{\circ}$ (131) increased, when comparing Experiments 5 and 14 . On the other hand, the peaks at $2 \theta \cong 51^{\circ}(220)$ and $2 \theta \cong 75^{\circ}$ (321) presented higher intensity in the results of Experiment 5 than in Experiment 14. This result indicates that the conditions used in Experiment 5 could have contributed to the production of a refined coating containing dispersed boehmite particles with no preferable orientation. 
Table 3. $2 \theta$ values and preferred orientation for the $\mathrm{Cu} / \mathrm{AlO}(\mathrm{OH})$ composite coatings produced under conditions of experiment 5 and 14 of Table 1.

\begin{tabular}{cccc}
\hline $2 \theta\left({ }^{\circ}\right)^{\mathrm{a}}$ & $2 \theta\left({ }^{\circ}\right)^{\mathrm{b}}$ & $\mathrm{Phases}$ & Orientations \\
\hline 27.889 & 27.733 & $\mathrm{AlO}(\mathrm{OH})$ & $(111)$ \\
& 43.297 & $\mathrm{Cu}$ & $(111)$ \\
43.034 & 43.538 & $\mathrm{AlO}(\mathrm{OH})$ & $(140)$ \\
44.073 & 44.673 & $\mathrm{Fe}$ & $(110)$ \\
45.946 & 45.788 & $\mathrm{AlO}(\mathrm{OH})$ & $(131)$ \\
49.873 & 49.211 & $\mathrm{AlO}(\mathrm{OH})$ & $(200)$ \\
50.911 & 50.225 & $\mathrm{AlO}(\mathrm{OH})$ & $(041)$ \\
51.543 & 51.594 & $\mathrm{AlO}(\mathrm{OH})$ & $(220)$ \\
66.485 & 66.121 & $\mathrm{AlO}(\mathrm{OH})$ & $(180)$ \\
73.549 & 74.130 & $\mathrm{Cu}$ & $(220)$ \\
75.197 & 75.654 & $\mathrm{AlO}(\mathrm{OH})$ & $(321)$ \\
82.059 & 82.017 & $\mathrm{AlO}(\mathrm{OH})$ & $(142)$ \\
& 82.333 & $\mathrm{Fe}$ & $(211)$ \\
88.897 & 89.233 & $\mathrm{Cu}$ & $(311)$ \\
95.330 & 88.864 & $\mathrm{AlO}(\mathrm{OH})$ & $(152)$ \\
& 95.139 & $\mathrm{Cu}$ & $(222)$ \\
\hline
\end{tabular}

${ }^{\mathrm{a}}$ observed; ${ }^{\mathrm{b}}$ literature.

\subsubsection{Chemical and Morphological analysis}

Although small amounts of boehmite were detected in the coatings, the chemical composition results in Table 2 show that the coating produced under the conditions of Experiments 5 and 14 presented a higher corrosion resistance than that of the bare steel substrate. It was an expected result, as the ceramic nanoparticles are known to be able to fill the pores and defects of the metallic coatings, increasing their corrosion resistance ${ }^{19,21}$. Additionally, the presence of AA as a leveling additive may also have contributed to this effect ${ }^{37,55}$.

These results also suggest that an increase in the $\boldsymbol{j}$ values and a decrease in $\boldsymbol{S}$ could enhance the particle incorporation in the composite coatings. An increase in $\boldsymbol{j}$ may favor the tendency for adsorbed nanoparticles to arrive at the cathode surface. This observation is in agreement with the Guglielmi model $^{13}$. Besides, a decrease in $\boldsymbol{S}$ values may also prevent loose boehmite particles adsorbed onto the electrode surface from being removed from the electrode.

However, the small differences observed in the content of $\mathrm{AlO}(\mathrm{OH})$ in the coatings led to distinct anticorrosive performance, as both the $\boldsymbol{R}_{\boldsymbol{p}}$ and $\boldsymbol{R}_{c t}$ values decreased as the $\%$ wt. $\mathrm{AlO}(\mathrm{OH})$ increased. In fact, the coating produced under the conditions of Experiment 14 presented a worse anticorrosive performance, when compared to the copper coating/steel substrate system. This unexpected result can be justified by the presence of small copper crystallites surrounded by agglomerated $\mathrm{AlO}(\mathrm{OH})$ particles. It is likely that, in this very fine microstructure, atoms from grain boundaries are readily and rapidly dissolved. Furthermore, the prevention of local corrosion and pit formation, obtained by the incorporation of nanoparticles, is disrupted due to their agglomeration ${ }^{19}$.

Figure 6 present SEM image of the surface morphology of the composite coating obtained under condition of Experiment 5.

Figure 6A shows that the boehmite particles are randomly dispersed on the coating surface, corroborating the results presented earlier suggesting that a refined microstructure was obtained. Even though high value of $\boldsymbol{S}$ was used, it was not high enough to remove the particles that are not completely adsorbed at the cathode ${ }^{18}$. However, some particles can also be observed in the inner part of the coating, as presented in the magnification of a surface defect shown in Figure 6B. This result indicates that the boehmite particles could have been incorporated in the coating by different mechanisms ${ }^{21}$.

\subsubsection{Nanohardness analysis}

The nanohardness values of the selected $\mathrm{Cu} / \mathrm{AlO}(\mathrm{OH})$ composite coatings is also presented in Table 2 and it is possible to observe that, as well as the anticorrosive properties, the hardness of these composite coatings are related with the $\mathrm{AlO}(\mathrm{OH})$ nanoparticle content. The nanohardness of the selected composite coatings increased with the \%wt. $\mathrm{AlO}(\mathrm{OH})$ particles. Similar results were verified for $\mathrm{Ni}-\mathrm{Co} / \mathrm{SiC}$ composite deposition ${ }^{9}$. However, the hardness value of the coating produced under the conditions of Experiment 5 was smaller than that of pure copper coating. The effect of the leveling agent (AA) could also contributed to this effect, as this additive decreases the amount of defects in copper coatings ${ }^{37,52,55}$.

It is interesting to observe that the increase in nanohardness is in opposition to the increase in the anticorrosive protection of the coatings. It could be explained by the reason that, the nanoparticles co-deposited in metallic matrix might have restrained the growth of the metal grains and the plastic deformation of the matrix under loading, by refining the grains and dispersive strengthening effects. These effects became stronger as the particles content in the coating increased, thus enhancing the hardness of the composite coatings ${ }^{3,9,10}$. Under these conditions, it seems that the AA has not affected the amount of defects on the surface of the coatings.

\section{Conclusions}

The studied parameters ( $\boldsymbol{j}, \boldsymbol{S}$ and $\boldsymbol{t}$ ) affected significantly the deposition of the composite coatings and, consequently, their anticorrosive properties. It was observed that an increasing $\boldsymbol{S}$ and a simultaneous decreasing $\boldsymbol{j}$ and $\boldsymbol{t}$ allowed the production of $\mathrm{Cu} / \mathrm{AlO}(\mathrm{OH})$ composite coatings presenting anticorrosive properties when compared to the bare steel substrate. However, only the composite coating produced under the conditions of Experiment 5 of Table $1(\boldsymbol{S}=1300$ rpm, $\boldsymbol{t}=120$ minutes, $\boldsymbol{j}=7.0 \mathrm{~A} \mathrm{~m}^{-2)}$ presented anticorrosive properties when compared to pure copper coating. 

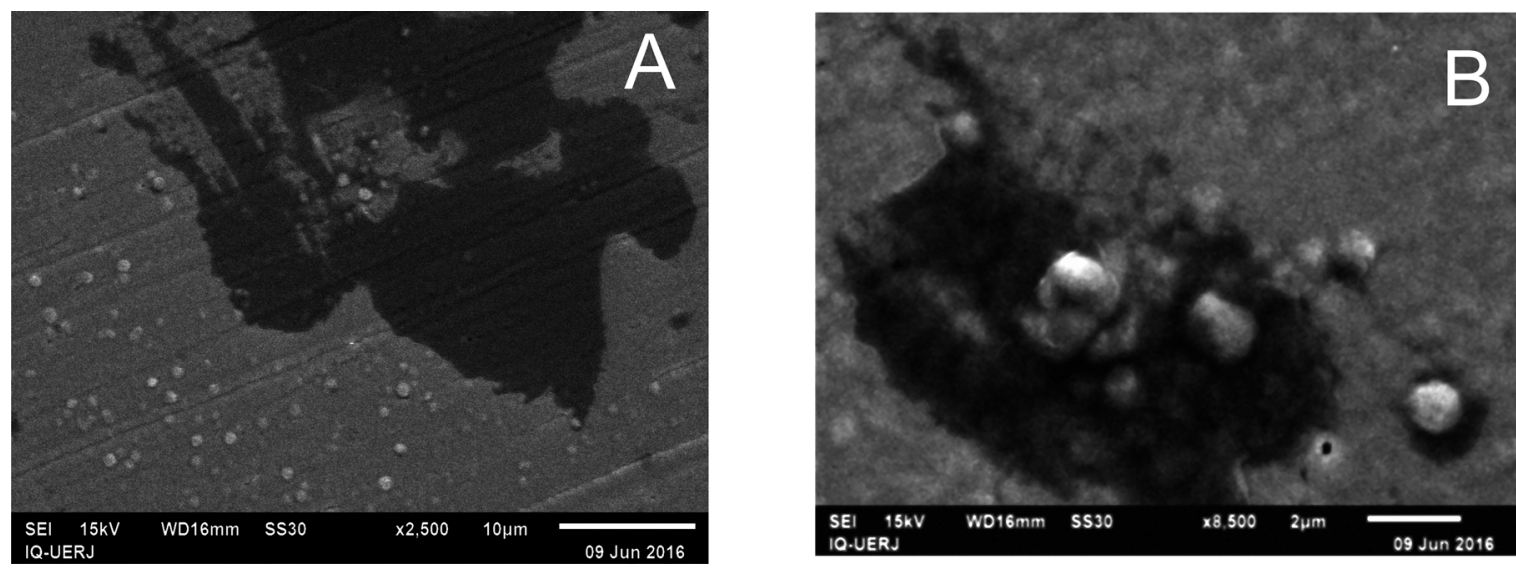

Figure 6. Surface morphology of the coating produced under the conditions of Experiment 5 of Table 1: (A) $2500 \mathrm{x}$ and (B) $8500 \mathrm{x}$.

In addition, it has been observed that the $\boldsymbol{R}_{p}$ and $\boldsymbol{R}_{c t}$ values tended to increase as the content of $\mathrm{AlO}(\mathrm{OH})$ particles incorporated in the composite coatings decreased, while the nanohardness of the coatings varied in the opposite direction. Therefore, the conditions used in this work were not able to produce a coating that could present both hard and anticorrosive characteristics.

The best corrosion resistant coating $\left(\boldsymbol{R}_{p}=211.05 \Omega\right.$ and $\boldsymbol{R}_{c t}=221.00 \Omega$ ), also presented the lowest hardness value $(180.08 \pm 6.88 \mathrm{HV})$ and it was obtained under the conditions of Experiment 5. The presence of the leveling additive AA changed the deposition process of the composite coatings. Therefore, the conditions used in Experiment 5 to deposit the coatings enhanced the production of refined composite coatings, with small amounts of defects, containing dispersed boehmite particles without preferable orientation. On the other hand, the coating produced from Experiment $14(\boldsymbol{S}=$ $1150 \mathrm{rpm}, \boldsymbol{t}=38$ minutes, $\boldsymbol{j}=14.0 \mathrm{~A} \mathrm{~m}^{-2)}$ showed the best hardness value (305.19 \pm 9.29$)$ and the lowest $\boldsymbol{R}_{p}(109.54$ $\Omega)$ and $\boldsymbol{R}_{t c}(121.00 \Omega)$ values.

\section{Acknowledgements}

The authors would like to thank the Rio de Janeiro Research Foundation (FAPERJ), the Brazilian National Research Council (CNPq), the State University of Rio de Janeiro (UERJ), and the Prociência Program for their financial support. We would also like to thank Mona Andrade Abdel Rehim and Priscila de Oliveira Pio Rodrigues, from Nacional Institute of Technology, for EDX, XRD and nanohardness analysis, Antônio Vitor de Castro Braga for technical support, and Isaac Mallet (LabMEV/UERJ) for the SEM analysis.

\section{References}

1. Feng Q, Li T, Zhang Z, Zhang J, Liu M, Jin J. Preparation of nanostructured $\mathrm{Ni} / \mathrm{Al}_{2} \mathrm{O}_{3}$ composite coatings in high magnetic field. Surface and Coatings Technology. 2007;201(14):6247-6252.

2. Faraji S, Rahim AA, Mohamed N, Sipaut CS. A study of electroless copper-phosphorus coatings with the addition of silicon carbide $(\mathrm{SiC})$ and graphite $\left(\mathrm{C}_{\mathrm{g}}\right)$ particles. Surface and Coatings Technology. 2011;206(6):1259-1268.

3. Sen R, Das S, Das K. Effect of stirring rate on the microstructure and microhardness of $\mathrm{Ni}-\mathrm{CeO}_{2}$ nanocomposite coating and investigation of the corrosion property. Surface and Coatings Technology. 2011;205(13-14):3847-3855.

4. Wu B, Xu BS, Zhang B, Lü Yh. Preparation and properties of $\mathrm{Ni} /$ nano- $\mathrm{Al}_{2} \mathrm{O}_{3}$ composite coatings by automatic brush plating. Surface and Coatings Technology. 2007;201(16-17):6933-6939.

5. Cordero-Arias L, Boccaccini AR, Virtanen S. Electrochemical behavior of nanostructured $\mathrm{TiO}_{2} /$ alginate composite coating on magnesium alloy AZ91D via electrophoretic deposition. Surface and Coatings Technology. 2015;265:212-217.

6. Sabri M, Sarabi AA, Naseri Kondelo SM. The effect of sodium dodecyl sulfate surfactant on the electrodeposition of $\mathrm{Ni}$ alumina composite coatings. Materials Chemistry and Physics. 2012;136(2-3):566-569.

7. Musiani M. Electrodeposition of composites: an expanding subject in electrochemical materials science. Electrochimica Acta. 2000;45(20):3397-3402.

8. Wu G, Li N, Zhou D, Mitsuo K. Electrodeposited Co-Ni$\mathrm{Al}_{2} \mathrm{O}_{3}$ composite coatings. Surface and Coatings Technology. 2004; 176(2):157-164.

9. Shi L, Sun C, Gao P, Zhou F, Liu W. Mechanical properties and wear and corrosion resistance of electrodeposited Ni$\mathrm{Co} / \mathrm{SiC}$ nanocomposite coating. Applied Surface Science. 2006;252(10):3591-3599. 
10. Borkar T, Harimkar SP. Effect of electrodeposition conditions and reinforcement content on microstructure and tribological properties of nickel composite coatings. Surface and Coatings Technology. 2011;205(17-18):4124-4134.

11. Gurrappa I, Binder L. Electrodeposition of nanostructured coatings and their characterization - a review. Science and Technology of Advanced Materials. 2008;9(4):043001. DOI: 10.1088/1468-6996/9/4/043001

12. Celis JP, Roos JR, Buelens C. A Mathematical-Model for the Electrolytic Codeposition of Particles with a Metallic Matrix. Journal of the Electrochemical Society. 1987;134(6):1402-1408.

13. Guglielmi N. Kinetics of the Deposition of Inert Particles from Electrolyte Baths. Journal of the Electrochemical Society. 1972;119(8):1009-1012.

14. Berçot P, Peña-Muñoz E, Pagetti J. Electrolytic composite Ni-PTFE coatings: an adaptation of Guglielmi's model for the phenomena of incorporation. Surface and Coatings Technology. 2002;157(2):282-289.

15. Fransaer J, Celis JP, Roos JR. Analysis of the Electrolytic Codeposition of Non-Brownian Particles with Metals. Journal of Electrochemical Society. 1992;139(2):413-425.

16. Vereecken P, Shao I, Searson P. Particle Codeposition in Nanocomposite Films. Journal of the Electrochemical Society. 2000;147(7):2572-2575.

17. Hwang BJ, Hwang CS. Mechanism of Codeposition of Silicon Carbide with Electrolytic Cobalt. Journal of the Electrochemical Society. 1993;140(4):979-984.

18. Tuaweri TJ, Wilcox GD. Behaviour of $\mathrm{Zn}-\mathrm{SiO}_{2}$ electrodeposition in the presence of $\mathrm{N}, \mathrm{N}$-dimethyldodecylamine. Surface and Coatings Technology. 2006;200(20-21):5921-5930.

19. Szczygiel B, Kolodziej M. Composite $\mathrm{Ni} / \mathrm{Al}_{2} \mathrm{O}_{3}$ coatings and their corrosion resistance. Electrochimica Acta. 2005;50(20):41884195 .

20. Stankovic VD, Gojo M. Electrodeposited composite coatings of copper with inert, semiconductive and conductive particles. Surface and Coatings Technology. 1996;81(2-3):225-232.

21. Lekka M, Zendron G, Zanella C, Lanzutti A, Fedrizzi L, Bonora PL. Corrosion properties of micro- and nanocomposite copper matrix coatings produced from a copper pyrophosphate bath under pulse current. Surface and Coatings Technology. 2011;205(11):3438-3447.

22. Lee HK, Lee HY, Jeon JM. Codeposition of micro- and nanosized $\mathrm{SiC}$ particles in the nickel matrix composite coatings obtained by electroplating. Surface and Coatings Technology. 2007;201(8):4711-4717.

23. Baghery P, Farzam M, Mousavi AB, Hosseini M. Ni-TiO nanocomposite coating with high resistance to corrosion and wear. Surface and Coatings Technology. 2010;204(23):38043810 .

24. Garcia I, Conde A, Langelaan G, Fransaer J, Celis JP. Improved corrosion resistance through microstructural modifications induced by codepositing SiC-particles with electrolytic nickel. Corrosion Science. 2003;45(6):1173-1189.
25. Malfatti CF, Veit HM, Menezes TL, Ferreira JZ, Rodrigues JS, Bonino JP. The surfactant addition effect in the elaboration of electrodepositated NiP-SiC composite coatings. Surface and Coatings Technology. 2007;201(14):6318-6324.

26. Rezende TGL, Cesar DV, Lago DCB, Senna LF. A review of Corrosion Resistance Nanocomposite Coatings. In: Mohamed AMA, Golden TD, eds. Electrodeposition of Composite Materials. Kijeka: InTech; 2016. p. 147-185.

27. Chen L, Wang L, Zeng Z, Zhang J. Effect of surfactant on the electrodeposition and wear resistance of $\mathrm{Ni}-\mathrm{Al}_{2} \mathrm{O}_{3}$ composite coatings. Materials Science and Engineering: A. 2006;434(12):319-325.

28. Zamblau I, Varvara S, Muresan LM. Corrosion behavior of $\mathrm{Cu}-\mathrm{SiO}_{2}$ nanocomposite coatings obtained by electrodeposition in the presence of cetyltrimethyl ammonium bromide. Journal of Materials Science. 2011;46(20):6484-6490.

29. Sohrabi A, Dolati A, Ghorbani M, Monfared A, Stroeve P. Nanomechanical properties of functionally graded composite coatings: Electrodeposited nickel dispersions containing silicon micro and nanoparticles. Materials Chemistry and Physics. 2010;121(3):497-505.

30. Ferreira FBA, Silva FLG, Luna AS, Lago DCB, Senna LF. Response surface modeling and optimization to study the influence of deposition parameters on the electrodeposition of $\mathrm{Cu}-\mathrm{Zn}$ alloys in citrate medium. Journal of Applied Electrochemistry. 2007;37(4):473-481.

31. Senna LF, Luna AS. Experimental Design and Response Surface Analysis as Available Tools for Statistical Modelling and Optimization of Electrodeposition Processes. In: Sebayang D, Hasan SBH, eds. Electroplating. Rijeka: InTech; 2012. p. 147-166.

32. Santana RAC, Prasad S, Campos ARN, Araújo FO, da Silva GP, de Lima-Neto P. Electrodeposition and corrosion behaviour of a Ni-W-B amorphous alloy. Journal of Applied Electrochemistry. 2006;36(1):105-113.

33. Santana RAC, Prasad S, Moura ES, Campos ARN, da Silva GP, de Lima-Neto P. Studies on electrodeposition of corrosion resistant Ni-Fe-Mo alloy. Journal of Materials Science. 2007;42(7):2290-2296.

34. Rabiot D, Caire JP, Nguyen B, Chainet E, Gerard F. Optimizing an electrochemical deposition process by use of design of computer experiments. Analusis. 1998;26(8):281-283.

35. Derringer G, Suich R. Simultaneous Optimization of Several Response Variables. Journal of Quality Technology. 1980;12(4):214219.

36. Silva FLG, Garcia JR, Cruz VGM, Luna AS, Lago DCB, Senna LF. Response surface analysis to evaluate the influence of deposition parameters on the electrodeposition of $\mathrm{Cu}-\mathrm{Co}$ alloys in citrate medium. Journal of Applied Electrochemistry. 2008;38(12):1763-1769.

37. de Farias LT, Luna AS, do Lago DCB, de Senna LF. Influence of catholic current density and mechanical stirring on the electrodeposition of $\mathrm{Cu}-\mathrm{Co}$ alloys in citrate bath. Materials Research. 2008;11(1):1-9. 
38. Hu CC, Bai A. Optimization of Hydrogen evolving activity on Nickel-Phosphorus Deposits using Experimental Strategies. Journal of Applied Electrochemistry. 2001;31(5):565-572.

39. Hu CC, Bai A. Composition control of electroplated nickelphosphorus deposits. Surface and Coatings Technology. 2001;137(2-3):181-187.

40. Hu CC, Tsay CH, Bai A. Optimization of the hydrogen evolution activity on zinc-nickel deposits using experimental strategies. Electrochimica Acta. 2003;48(7):907-918.

41. Garcia JR, do Lago DCB, Silva FLG, D’Elia E, Luna AS, de Senna LF. Statistic evaluation of cysteine and allyl alcohol as additives for $\mathrm{Cu}-\mathrm{Zn}$ coatings from citrate baths. Materials Research. 2013;16(2):392-403.

42. Manahan SE. Polarographic Investigation of the Allyl Alcohol Complex of Copper(I) in Aqueous Solution. Inorganic Chemistry. 1966;5(3):482-483.

43. Silva FLG, do Lago DCB, D’Elia E, Senna LF. Electrodeposition of $\mathrm{Cu}-\mathrm{Zn}$ alloy coatings from citrate baths containing benzotriazole and cysteine as additives. Journal of Applied Electrochemistry. 2010;40(11):2013-2022.

44. Senna LF, Díaz SL, Sathler L. Electrodeposition of copper-zinc alloys in pyrophosphate-based electrolytes. Journal of Applied Electrochemistry. 2003;33(12):1155-1161.

45. Senna LF, Díaz SL, Sathler L. Hardness analysis and morphological characterization of copper-zinc produced in pyrophosphatebased electrolytes. Materials Research. 2005;8(3):275-279.

46. Lima TG. Eletrodeposição de revestimentos funcionais compósitos Cu/partículas de óxidos de alumínio. [Dissertation]. Rio de Janeiro: Chemical Engineering Graduate Program. State University of Rio de Janeiro; 2013.
47. Barcelos AML, Luna AS, Ferreira NA, Braga AVC, Lago DCB, Senna LF. Corrosion evaluation of orthodontic wires in artificial saliva solutions by using response surface methodology. Materials Research. 2013;16(1):50-64.

48. Massart DL, Vandeginste BGM, Buydens LMC, de Jong P, Lewi J, Smeyers-Verbeke J. Handbook of Chemometrics and Qualimetrics: Part A. Amsterdam: Elsevier; 1997.

49. Montgomery DC. Design and Analysis of Experiments. Hoboken: Wiley; 2005.

50. Bakhit B, Akbari A, Nasirpouri F, Hosseini MG. Corrosion resistance of $\mathrm{Ni}-\mathrm{Co}$ alloy and $\mathrm{Ni}-\mathrm{Co} / \mathrm{SiC}$ nanocomposite coatings electrodeposited by sediment codeposition technique. Applied Surface Science. 2014;307:351-359.

51. Vagramyan TA. Electrodeposition of Alloys: Mechanism of Simultaneous Reaction of Metal Ion. In: Kruglikov SS, ed. Electrochemistry. Jerusalem: Israel Program of Scientific Translation; 1970.

52. Oniciu L, Muresan L. Some fundamental aspects of leveling and brightening in metal electrodeposition. Journal of Applied Electrochemistry. 1991;21(7):565-574.

53. Sürme Y, Gürten AA, Bayol E, Ersoy E. Systematic corrosion investigation of various $\mathrm{Cu}-\mathrm{Sn}$ alloys electrodeposited on mild steel in acidic solution: Dependence of alloy composition. Journal of Alloys and Compounds. 2009;485(1-2):98-103.

54. Alfantazi AM, El-Sherik AM, Erb U. The role of nickel in the morphology evolution of pulse plated $\mathrm{Zn}-\mathrm{Ni}$ alloy coatings. Scripta Metallurgica et Materialia. 1994;30(10):1245-1250.

55. Vargalyuk VF, Loshkarev YM, Polonskii VA, Khoroshavkina NV. Kinetics and mechanism of copper (II) in the presence of certain unsatured organic compounds - allyl alcohol. Sovietic Electrochemistry. 1986;22(9):1229-1231. 